\title{
Analyzing Linguistic Errors in Writing an English Letter: A Case Study of Indonesian Undergraduate Students
}

\author{
Sependi Napitupulu \\ Department of English Literature, Faculty of Letters, Methodist University of Indonesia, Medan, Indonesia
}

Email address:

senuy.napit@gmail.com

\section{To cite this article:}

Sependi Napitupulu. Analyzing Linguistic Errors in Writing an English Letter: A Case Study of Indonesian Undergraduate Students. International Journal of Language and Linguistics. Vol. 5, No. 3, 2017, pp. 71-77. doi: 10.11648/j.ij11.20170503.12

Received: March 29, 2017; Accepted: April 4, 2017; Published: May 5, 2017

\begin{abstract}
This paper seeks to explore errors in Indonesian students' writing in English. Seventy five students in their second year of study at the Department of English Literature, Faculty of Letters, Methodist University of Indonesia, Medan, were involved in this study. Despite the fact that they have studied grammar in the first semester at the University and several years in High School, students still face problems in writing in English. This study will elaborate on types of errors on students' writing so as to make them aware of each type of errors before composing a text in English. In gathering the data needed, students were asked to write a letter with a maximum of 90 words to a property agent requesting for a specific home they wish to buy. Their writings afterwards were analyzed in terms of linguistic errors as proposed by Hubbard et al. (1996). These include grammatical, syntactic, substance, and lexical errors. This study revealed that students committed $42.4 \%$ of grammatical errors, $26.7 \%$ of syntactic errors, $17.9 \%$ of substance errors, $13 \%$ of lexical errors. Based on the discussion of the findings, it is concluded that Indonesian students in this study committed a great number of errors due to first language transfer.
\end{abstract}

Keywords: Errors in Writing, EFL Students, Linguistic Errors, Error Analysis

\section{Introduction}

Without a doubt, EFL learners are having a hard time writing in English since their exposure to English is limited. Olasehinde (2002) argues that it is inevitable that learners make errors. He also suggested that errors are unavoidable and a necessary part of the learning curve. The absence of self-awareness in improving their English skills especially in writing is what seems to be the problem all the while. They tend to rely on their perceived knowledge gained from school education system in which they are taught grammar and tenses. In Indonesia particularly, students have been introduced to grammar lessons since junior high school, and yet, writing has always seemed to be the most difficult part even when they are at the university level or at a major of English education or English literature. Wee, et. al (2009:016) state that most EFL learners tend to commit errors in writing regardless of a long period of English study. According to Lalande (1982:140), despite the fact that the students have studied certain rules of grammar, "some students exhibit remarkable consistency: they commit the same types of errors from one essay to the next".

Besides errors in grammar, in writing, students tend to be short of ideas. Their minds wander and tend to take a long time to produce an essay. This is due to the lack of writing practice at school and self pratice. As Hyland (2003) and Ferris (2002) put it, EFL writing is generally shorter, less cohesive and fluent, and contains more errors. This is evident as seen in students' writing in present research, where when they were asked to compose a maximum of 90 words, yet some produced in between fifty to seventy words in total. In addition to lack of number of words, they also inevitably produced easy-to-spot errors.

Sawalheh (2013:3) stated that researchers interested in error analysis observed that errors are beneficial for both learners and teachers as it provides information to the teachers on students errors. This helps the teachers in three ways, firstly to correct their errors, secondly to improve their teaching and thirdly to focus on those area that need reinforcement (Al-haysoni, 2012).

Based on this background of study, it is therefore imperative to conduct a research on students' errors in 
English writing especially letter writing, as Corder (1967:167) puts forth that the errors made by the ESL/EFL learners provide to the researcher evidence of how language is learned or acquired, what strategies or procedures the learner is employing in the discovery of the language.

\subsection{Aim of Research}

This research aims to investigate errors made by the second year students of English Literature Department, Faculty of English Letters, Methodist University, Medan, Indonesia in writing an English letter.

\subsection{Research Question}

What linguistic errors do students commit in writing an English Letter?

\section{Literature Review}

\subsection{Error Analysis}

Error Analysis (EA) is concerned with the analyses of the errors made by L2 learners by comparing the learners' acquired norms with the target language norms and explaining the identified errors (James, 1998). From the perspective of norm or well-formedness of a sentence, error is regarded as "an infringement or deviation of the code of the formal system of communication through which the message is conveyed" (Catalan, n. d.:66).

Richards \& Schmidt (2002) defined Error Analysis (EA) as "a technique for identifying, classifying and systematically interpreting the unacceptable forms of a language in the production data of someone learning either a second or foreign language." Such systematic analysis of errors eventually provides useful insights about the system operating in the learners' mind and reveals the learners' knowledge about the grammatical systems of the target language. By identifying what is exactly lacking in the learners' competence, EA brings the problem areas to the attention of teachers, syllabus designers and textbook writers, and suggests remedial action to overcome the mismatch between knowledge of the learner and the demands of the situation. An error refers to an identifiable alteration of the grammatical elements of a native speaker, presenting the learners' competence in the target language (Brown, 2007:257-259).

\subsection{Procedures in Analyzing Errors}

According to Ellis (1985) EA is usually operated on the production data of language learners (compositions, speeches, etc.), and any EA activity entails the following procedures:

a. Defining a corpus of language

b. Identifying errors in the corpus

c. Classifying the errors

d. Explaining the errors

Defining a corpus of language: The first step in EA involves collecting and defining a set of utterances produced by L2 learners.

Error identification

Ellis (1997) claims that comparing the sentences learners produce with what the normal or 'correct' sentences in the target language, which correspond with them enable us to identify errors. This process involves “...a comparison between what the learner has produced and what a native speaker counterpart would produce in the same context" (Ellis \& Barkhuizen, 2005:58). Errors are those sentences which are ill-formed grammatically or well-formed grammatically but inappropriate for a particular context. This is to say that superficial well-formedness only does not make a sentence error-free; it also needs to be appropriate in the communication context. After identifying the erroneous utterance, it will be possible to compare the reconstruction with the original erroneous utterance and then we can describe the differences in terms of the grammar of the target language.

Describing errors

The description procedure involves specifying how the forms produced by the learner differ from those produced by the learner's native speaker counterparts in the same context. The most useful and commonly used taxonomies for error descriptions are linguistic taxonomy, surface structure taxonomy, communicative effect taxonomy, and comparative analysis taxonomy. The following discussion of error description taxonomies is based on the presentation given in (Dulay, et. al., 1982:150-163).

i) Linguistic taxonomy

This classification of learner errors is on the basis of the linguistic component or item (phonology/orthography, grammar, semantics, lexicon, and discourse) that is affected by an error. This taxonomy improves teaching since it uses well-established grammatical categories which are utilized to organize language lessons in textbooks and workbooks.

ii) Surface structure taxonomy

This taxonomy works on mechanisms in which surface forms are modified or altered in erroneous utterances. There are four main ways in which learners alter target forms.

a. Addition errors: such errors refer to the presence of an element or a form which must not appear in a wellformed utterance. Addition errors are sub-categorized into: regularization i.e applying rules used to produce the regular ones to those exceptions to the rules; doublemarking, a kind of addition error in which one feature is marked at two levels; simple additions are those which are neither regularizations nor double-markings.

b. Omission errors: the absence of an item that must appear in a well- formed utterance.

c. Misordering errors: caused by incorrect placement of a morpheme or group of morphemes in a given utterance.

d. Misformation errors: refer to the use of a wrong form of a morpheme or a structure in an utterance.

Explaining errors

Saville (2006) emphasized the idea that accounting for, why an error was made is the most important step in any 
attempt to understand the process of second language acquisition and to improve the way a second language is learned (pedagogical purpose). Generally, researchers of second language learning have identified two sources of errors: interlingual and intralingual factors. Explained below are interlingual and intralingual errors:

\subsection{Interlingual Errors}

In this type, errors are caused by mother tongue interference as stated by Richards (1971:205) where interlingual errors are the errors caused by the interference of the native language. These errors are the results of the learners' application of the native language elements in their spoken or written performances of the target language. Indonesian learners of English tend to have it in their mind that certain word in English is the same with certain word in Indonesian, such as the word "baggage" misunderstood with the word "bagasi". In this case, learners carry over the existing knowledge of their native language to the performance of the target language (Ellis, 1997: 28). In most cases, it is inevitable to learn a foreign language solely without depending on some linguistic features of the language which has already acquired. Ellis (2008:350) also states that at any rate, the interference can occur in various areas of linguistics components including phonology, morphology, grammar, syntax, lexis and semantics.

\subsection{Intralingual Errors}

These errors are referred to the errors that occur because of the ineffective traits of learning such as faulty application of rules and unawareness of the restrictions of rules (Richards, 1971:206). The intralingual errors, therefore, are irrelevant to the native language interference, but led by the target language itself. In the language learning process, these errors normally occur when the learners have acquired insufficient knowledge (Kaweera, 2013:13).

\subsection{Related Work}

In the past few years, there has been a large and growing amount of literature on error analysis. Just recently, Sermsook, et. al (2017) conducted a similar research with the purposes of examining the language errors in a writing of English major students in a Thai university and exploring the sources of the errors. Their study discovered that the most frequently committed errors were punctuation, articles, subject-verb agreement, spelling, capitalization, and fragment, respectively. Interlingual interference, intralingual interference, limited knowledge of English grammar and vocabulary, and carelessness of the students were found to be the major sources of the errors.

Another study conducted by Phuket and Othman (2015) who explore the major sources of errors occurred in the writing of EFL students. It also investigates the types of errors and the linguistic level that presents the most errors in their writing. Their study discovered that the mostly frequent types of errors were translated words from Thai, word choice, verb tense, preposition, and comma. The errors derived from two sources: interlingual and intralingual. Interlingual or native language interference was found to be the dominant source of errors.

Alhaysony (2012) examined written samples of 100 firstyear female Arabic-speaking EFL students in the University of Ha'il. His findings showed that students made a considerable number of errors in their use of articles, especially, the omission errors. His study had a mixed finding because these errors included interlingual and intralingual transfer.

Ridha (2012) examined English writing samples of $80 \mathrm{EFL}$ college students and then categorized the errors according to the following taxonomy: grammatical, lexical/semantic, mechanics, and word order types of errors. The results showed that most of the students' errors can be due to L1 transfer. Furthermore, she found that most of the learners rely on their mother tongue in expressing their ideas.

\section{Methodology}

This study is qualitative in nature which uses the method of content analysis to gather the research results. The content analysis is widely used in social sciences research. This method is used for analyzing the contents of any texts and the texts with errors committed by the students.

\subsection{Research Participants}

Participants in this study are undergraduate students. Since the author is currently a faculty member at the department of English literature, Faculty of Letters, Methodist University, Medan, Indonesia, and due to limited time and energy, then a total of seventy five undergraduate students in the second year of their study at the department of English literature, Faculty of Letters, Methodist University, Medan, Indonesia were purposely chosen. This selection is done since they have taken the subject of writing in the first year of study. During the subject of writing in the first year of study, they were taught of how to write a letter in English. Thus, it is best assumed that they have the basic knowledge of letter writing in English.

\subsection{Technique of Collecting Data}

As for the purpose of this particular study, the students were individually assigned a particular task of writing a request letter to a property agent regarding their plan to move out to a new house in another city. To give them plenty of time of doing the assignment, they were given a deadline withing a week to submit their assignments timely.

\subsection{Technique of Analyzing Data}

Having collected their individual tasks, the researcher investigated respective students' letter writings thoroughly with the aim of discovering any ill-formed sentences. Then, an analysis was done by detecting the errors and classifying them under the umbrella of Hubbard's et al. (1996) 
classification of errors namely grammatical, syntactic, substance, and lexical errors. They are subsequently counted to find their frequencies and percentages which later to be put in a table and a graph.

\section{Findings and Discussions}

Having analyzed the whole data, the following results are found.

Table 1. Proportion of Errors Committed by Students.

\begin{tabular}{llll}
\hline Catergory & Sub Categories & Frequency & Percentage \\
\hline \multirow{4}{*}{ Grammar } & Propositions & 59 & 27.2 \\
& Tenses & 12 & 5.5 \\
& Articles & 21 & 9.7 \\
Syntax & Subject verb agreement & 32 & 14.7 \\
& Word order & 26 & 12 \\
Substance & Capitalization & 9 & 4.14 \\
& Punctuation & 11 & 5 \\
Lexical & Spelling & 19 & 8.75 \\
Total & Word choice & 28 & 13 \\
\hline
\end{tabular}

Of the 75 students, data of 217 errors were found. The dominant error classification was preposition use with a total of fifty nine errors, while, the least dominant error was capitalization with the total of nine errors. Thus, based on each category, the total errors can be classified in the following graph:

\section{Percentage of Each Error Category}

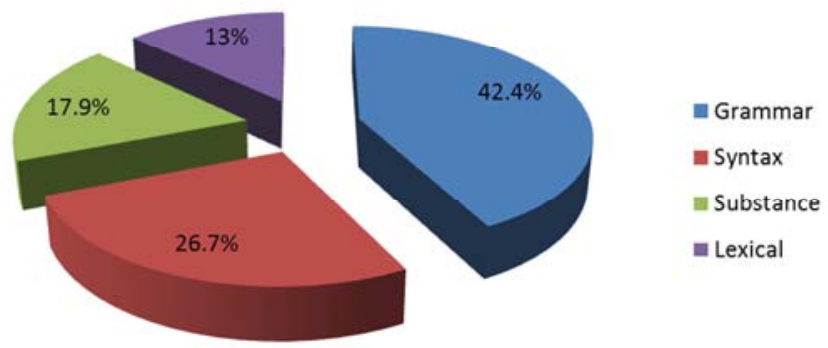

Figure 1. Percentage of Errors in Each Error Category.

As shown above, grammatical errors are the most dominant error with $42.4 \%$ errors, second most dominant errors are syntactic errors with $26.7 \%$ errors, followed by substance errors with $17.9 \%$ errors, and the least dominant errors are lexical errors with $13 \%$ errors.

Those errors classification is further explained below:

\subsection{Grammatical Errors}

Propositions

Finnegan (2008) defines prepositions as units, describing relationship between two nd the other being a landmark in the background. Gvarishvili (2012:1567) states that prepositions are especially difficult for the English language learner when L1 is not cognate language and belongs to synthetic, agglutinative type of languages, where the functions of preposition may be performed either by inflections, postpositions or other lexical units.

Quite a number of participants in this study demonstrated confusion for the right usage of prepositions as shown in the examples below.

1. Error identification: in the end of this month

Correction: at the end of this month

2. Error identification: This house has 2 bedrooms on lower floor

Correction: This house has 2 bedrooms in the lower floor

In the first example, the student misused the preposition "in" instead of "at" for the phrase of "the end of this month". In the second example, the student has misused a preposition "on" with "in" to indicate a certain level of floor in a house. The use of preposition in English is not easy for Indonesian students to remember since each preposition in English is used differently for different noun following it.

Singular/plural nouns:

This type of error is commonly found is students' writing. Unconsciously, students have been accustomed to writing singular nouns instead of plural nouns as shown in the following example.

1. Error identification: Have 2 or more bedroom

Correction: Have 2 or more bedrooms

2. Error identification: Can I order one your house ...........

Correction: Can I order one of your houses ....

In the first example above, student committed a mistake on the plural form of the noun. As seen on the example sentence, since the number of bedroom is more than one, then the following noun should be a plural form. Seen above, 2 or more bedroom was written as singular by the student instead of a plural noun. This singular or plural noun error is typical in Indonesian students' writing as they are not conscious of the rule of grammar in English.

In the second example above, this is also is an effect of the daily use of Indonesian language. In this case, as mentioned in a methodology of research, students wrote a letter to a property agent asking for a new house to live in. It is obvious that the property agent has more than one houses, a number of houses. Therefore, in the second example above, the student should have written ".. one of your houses....".

Tenses

Errors of wrong tense or wrong verb happen when a learner uses the wrong verb tense in a certain sentence. This study found that the participants were not aware of applying the correct tense to the verb in the sentences as shown in the example below.

Error identification: My family and I was very happy

Correction: My family and I will be very happy

This statement is at the end of the participants' letter in which they tell the property agent that they will be happy once they get the home they expected. Therefore, in this case, the correct tense would be future tense.

Articles

An article is a word that is used with a noun to indicate the type of reference being made by the noun. English has two 
articles: "the" and "a/an". "The" is used to refer to specific or particular nouns; a/an is used to modify nonspecific or nonparticular nouns. We call "the" the definite article and "a/an" the indefinite articles.

In the error classification of article use, students tend to forget to place an article before a countable noun as can be seen in the following example.

Error identification: large yard

Correction: a large yard

As with problems with singular/plural noun, problems with article are also common in student writing. They have always been mistaken as to which article indicates a singular noun or a plural noun.

\subsection{Syntactic Errors}

Syntactic errors in this study are classified into several sub-categories, viz noun/pronoun, word order, subject-verb agreement. Shown below are examples of syntactic errors.

Noun/pronoun

A pronoun is a word that takes the place of a noun. We use pronouns to make sentences less weighty and less repetitive. They are classified into several types, i.e., the personal pronoun, the demonstrative pronoun, the interrogative pronoun, the indefinite pronoun, the relative pronoun, the reflexive pronoun, and the intensive pronoun.

Error identification: Estate which that have 3 toilet,

Correction: Estate that has 3 toilets,

In the above example, student commits error in the use of relative pronoun. The student used the doubled relative pronoun (that and which) in the above clause which in the end making the sentence confusing to the reader.

Word order

Word order is the syntactic arrangement of words in a sentence, clause, or phrase.

Error identification: The houseyard that is so green ideal for ..........

Correction: The green houseyard is ideal for

Students also have the tendency to misplace a relative pronoun in a sentence. In the above example, the stress in meaning is in the clause of "ideal for". Therefore, the sentence should be split by making the first sentence complete first before adding new information and before using "for" as a coordinating conjunction.

Subject Verb Agreement

Subjects and verbs must agree with one another in number (singular or plural). Thus, if a subject (the person or thing doing the action) is singular, its verb (the word representing the action) must also be singular; if a subject is plural, its verb must also be plural.

Error identification: I also wants a fenced house to comfort my family and me.

Correction: I also want a fenced house to comfort my family and me.

In the above example, student made a mistake on the form of the verb. Since the subject of the sentence is "I" then the verb which follows it should be a singular verb that ends with an $-\mathrm{s}$.

\subsection{Substance Errors}

Substance errors here are classified into punctuation, spelling, and capitalization. Shown below are examples of substance errors:

Punctuation

Correct use of punctuation has always been overlooked as is shown in the example below.

Error Identification: ....... 1 in kitchen, I hope....

Correction: ....... 1 in kitchen. I hope....

In the above example, student has misused a comma instead of a full stop. Full stops are used to mark the end of a sentence that is a complete statement, while a comma indicates a pause between parts of a sentence or separating items in a list. In the above example, the statement is finished with the phrase " 1 in the kitchen". The phrase "I hope" is a new statement which needs to be separated from the previous idea.

Spelling

Spelling means the act or process of writing words by using the letters conventionally accepted for their formation.

Error Identification: I want a large house with two floors, three badrooms,

Correction: I want a large house with two floors, three bedrooms,

The spelling "badroom" are found in quite a number of students' writing in this study. They think that the pronunciation "bad" has similar sound to the word "bedroom" in this context. Being unaware of this small mistake, their writing could be misleading information and hence the inquiry, which in this case they want to buy a house, may not be responded by the property agent.

Capitalization

Capitalization means writing a word with its first letter as a capital letter (upper-case letter) and the remaining letters in small letters (lower-case letters). Capitalization is another error that tends to be overlooked by EFL learners especially Indonesian students as shown in the example below:

1. Error identification: so, that's the picture of the condition of....

Correction: So, that's the picture of the condition of.....

2. Error identification: i will pay my order ....

Correction: I will pay my order .......

In the first example above, the word of "so" is placed at the beginning of the sentence, therefore, it should be capitalized. The student was not aware of this. While in the second example, the pronoun "I" has always been mistaken for "i" with small case letter. Indonesian students are mostly neglectful of this rule in English writing. As a result, quite a number of students committed this same mistake over and over again.

\subsection{Lexical Errors}

Lexical errors tend to happen since students are not willing to look up dictionaries, online resources, etc. Shown below are examples of lexical errors:

Word Choice 
1. Error identification: Baggage for cars

Correction: A garage for cars

2. Error identification: Signed,

Correction: Regards,

The above example shows that students are influenced by their Indonesian culture and context. As can be seen the student commits errors of word choice. The word "baggage" must have been confused with the word "bagasi" in Indonesian. Most likely, the student did not check the accuracy of the word meaning which leads to the serious error in English. In English, the word "baggage" means "all the suitcases and bags that you take with you when you travel". Another significant error student makes is ending the letter. Students are deeply influenced by Indonesian style of writing. As seen on the second example above, the word "signed" which in Indonesian means "tertanda" is literally transferred into "signed" in English. In a letter, it should be ended with either "Regards, Yours Truly, or Yours Sincerely". Quite a number of students committed this mistake.

The results of the present study indicate that students have developed errors due to their incomplete knowledge of English grammar and improper knowledge of letter writing. This is in line with Richards' (1971:209) argument who argues that developmental errors are the errors occur when "the learner attempting to build up hypotheses about the English language from his limited experience of it in the classroom or text-book". The author truly believes that errors in grammar as the dominant error in this study is without a doubt a number one error committed by Indonesian students, even if the research conducted in many universities across Indonesia. The simple rule of Indonesian grammar has somehow affected the way students of English in Indonesia think and jot their ideas down in paper using English. In the meantime, with regards to letter writing, Campanizzi $(2005:: 55)$ argues that letters that are written well maintain the goodwill of the recipient, while poorly written letters can alienate the recipient and lose business or clients).

\section{Conclusions}

Based on the discussion of the findings and the examples given, besides developmental errors students caused, it could also be concluded that Indonesian students in this study committed a great number of errors due to their first language (L1) transfer. This is in line with Ridha's (2012) findings where students' errors are most likely due to L1 transfer and students tend to rely on their mother tongue in expressing their ideas which cause them improper word choices and wrong sentence structures. In addition to that, the findings of this study strengthen the findings of Sermsook, et. al (2017) where most of EFL students tend to commit errors in punctuation, articles, subject-verb agreement, spelling, capitalization, and fragment.

\section{Suggestions}

\subsection{For Students}

In order to improve student's writing in English, several steps shall be applied, viz planning, drafting, revising \& editing. Based on researcher's experience, some tools might help students in revising and editing in particular can come from online resources such as Google Search. This free search engine is useful for looking up proper terminologies, correct ways of ending and beginning a letter, proper letter format, most commonly used phrases and clauses and even commonly used sentences in writing a letter in English. As such, students will most likely succeed in delivering the intended conversation to the target reader.

\subsection{For Future Researches}

Since this study was only conducted on students in one department/university and at one level of study and thus the results only reflect those writing skills of this limited investigated sample and cannot be necessarily generalized to all Indonesian University students, it is therefore of necessity for a more extensive study to be conducted that includes students from various universities in order to see the comparative results and more varied data resulted from them.

\section{References}

[1] Alhaisoni, M. (2012). An Analysis of Article Errors among Saudi Female EFL Students: A Case Study, Asian Social ScienceCanadian Center of Science and Education, 8(12), 55- 66.

[2] Alhaysony, M. (2012). An analysis of article errors among Saudi female EFL students: A case study Asian Social Science, 8(12), 55-66.

[3] Brown, H. (2007). Principles of language learning and teaching. New York: Pearson Education Inc.

[4] Campanizzi, J. (2005). Effective Writing for the Quality Professional. Creating Useful Letters, Reports, and Procedures. ASQ Quality Press Milwaukee, Wisconsin.

[5] Catalan, R. (n. d). Terms and Definitions of Errors in SLA. Accessed from www.raco.cat/index.php/bells/article/viewFile/102789/163499

[6] Corder, S. P. (1967). The significance of learner's errors. International Review of Applied Linguistics in Language Teaching, 5(4), 161-170.

[7] Dulay, H. C., et. al. (1982). Language Two. New York: Oxford University Ellis, R. (1985). Understanding Second Language Acquisition. Oxford: Oxford University Press.

[8] Ellis, R. (1997). Second language acquisition. New York, Oxford University Press.

[9] Ellis, R. (2008). The study of second language acquisition. Oxford, UK: Oxford University Press.

[10] Ellis, R., Barkhuizen, G. (2005). Analysing Learner Language. Oxford: Oxford University Ferris, D. (2002). Treatment of error in second language writing. Michigan, The University of Michigan Press. 
[11] Gvarishvili, Z. (2012). Interference of L1 prepositional knowledge in acquiring of prepositional usage in English. Akdeniz Language Studies Conference. Procedia Social and Behavioral Sciences Volume 70. Antalya, Turkey 9-12 May.

[12] Hubbard, P., et. al. (1996). A Training Course for TEFL. Oxford: Oxford University Press.

[13] Hyland, K. (2003). Second language writing. Cambridge: Cambridge University Press. Accessed from http://dx.doi.org/10.1017/CBO9780511667251.

[14] James, C. (1988). Errors in language learning use: Exploring error analysis. Harlow, Essex: Addison Wesley Longman Limited.

[15] Kaweera, C. (2013). Writing error: A review of interlingual and intralingual interference in EFL context. English Language Teaching, 6, 9-18.

[16] Lalande, J. (1982). Reducing Composition errors: An experiment. Modern language Journal, 66, 140-49. Accessed from http://dx.doi.org/10.1111/j.1540-4781.1982.tb06973.x.

[17] Olasehinde, M. O. (2002). Error analysis and remedial pedagogy. In Babatunde S. T. and D. S. Adeyanju (eds.). Language, meaning and society. Ilorin: Itaytee Press and Publishing Co., Nigeria Phuket, P. R. N, Othman, NB. O. (2015). Understanding EFL Students' Errors in Writing. Journal of Education and Practice. Vol.6, No.32.
[18] Richards, J. C. (1971). A non-contrastive approach to Error Analysis. English Language Teaching Journal, 25, 204-219.

[19] Richards, J. C., and Schmidt, R. (2002). Longman Dictionary of Language Teaching and Applied Linguistics. (4th ed.). London: Longman (Pearson Education).

[20] Ridha, N. (2012). The Effect of EFL Learners' Mother Tongue on their Writings in English: An Error Analysis Study. Journal of the College of Arts. University of Basrah, 60, 2245 .

[21] Saville, M., Troike (2006). Introducing Second Language Acquisition. Cambridge. Cambridge University Press Sawalmeh, M. H. M (2013). Error Analysis of Written English Essays: The case of Students of the Preparatory Year Program in Saudi Arabia. English for Specific Purposes World. Issue 40, vol. 14.

[22] Sermsook, K. et. al. (2017). An Analysis of Errors in Written English Sentences: A Case Study of Thai EFL Students. English Language Teaching; Vol. 10, No. 3.

[23] Wee, R., et. al. (2009). Verb-form errors in EAP writing. Educational Research and Review, 5, 016-023. 